\title{
Refractory Gastric Carcinoma
}

National Cancer Institute

\section{Source}

National Cancer Institute. Refractory Gastric Carcinoma. NCI Thesaurus. Code C147996.

Gastric carcinoma that does not respond to treatment. 